\title{
Grey-Box Modelling and Validation of APMS (Automated People Mover System) Train
}

\author{
Lucas Elbert Suryana ${ }^{1}$, Endra Joelianto ${ }^{2}$, and Yosi Agustina Hidayat ${ }^{3}$
}

${ }^{1}$ Instrumentation and Control Master Program Institut Teknologi Bandung, Bandung, Indonesia

${ }^{2}$ Instrumentation and Control Research Group Institut Teknologi Bandung, Bandung Indonesia

${ }^{3}$ Industrial System and Techno-Economy Research Group Institut Teknologi Bandung,

Bandung Indonesia

lucaselbert@gmail.com, ejoel@tt.itb.ac.id*,yosi@mail.ti.itb.ac.id

*Corresponding Author: ejoel@tf.itb.ac.id

Abstract: A grey-box model of an automated people mover system (APMS) is constructed in this paper. APMS is one of the urban transit constructions that is being constructed in Indonesia and used for connecting between terminals in the airport. The APMS model can be identified to obtain the mathematical representation of the full system by finding unknown parameters through the data measured from the installed system at the airport. Generalized reduced gradient (GRG) algorithm is operated to identify the model parameters. The model can then be used for verification and testing controller designs such as proportional-integralderivative (PID) or model predictive control (MPC), and energy-saving strategies. The obtained model is able to follow the dynamic of the real APMS with RMSE value 0.013.

Keywords: Grey-box model; APMS model; parameter estimation; GRG algorithm; data measurement

\section{Introduction}

Nowadays, train signaling system technology in Indonesia is experiencing rapid development with the creation of rail-based public transport infrastructure aimed at urban regions, known as urban transit. This signaling system technology is known as Communication-Based Train Control (CBTC). There are three urban transit constructions in Indonesia, for instance, Mass Rapid Transit (MRT), Light Rail Transit (LRT), and Automated People Movers System (APMS).

APMS, shown by Fig. 1, is a unique urban transit, as it only moves between terminals in the airport. Compared to MRT and LRT train, APMS uses rubber wheels instead of steel and has a lesser number of wagons. Indonesia's APMS named Soekarno-Hatta Airport Skytrain in Soekarno-Hatta International Airport, Jakarta. This APMS has a track of $3.05 \mathrm{~km}$ which serves passengers to commute between three terminals: Terminal 1, 2, and 3. However, APMS in Indonesia still operates by a driver even though all APMS lines are equipped with CBTC and have the capability to be fully driverless and automated.

The previous people mover is Aeromovel train also consists of two wagons used at Taman Mini Indonesia Indah, Jakarta, Indonesia since 1989 [1-4]. Aeromovel train moves on steel wheels using the air duct blown to a square plate (a piston) placed under each wagon. No driver is required to operate aeromovel. A complete control system is applied to control the air pressure along the hollow duct to move and to stop the aeromovel.

Well-known control methods such as the PID controller or linear quadratic regulator (LQR) could be used to operate APMS automatically. However, these control methods require mathematical models such as differential equations or state-space mathematical models [5]. Since the past, researchers have developed a train mathematical model. The development of this mathematical model began in the early 1900s when Schmidt and Dunn introduced a practical model of train-resistance based on the familiar train-resistance equation, the Davis equation in 1926.

Received: August $9^{\text {th }}, 2020$. Accepted: December $8^{\text {th }}, 2020$ DOI: $10.15676 /$ ijeei.2020.12.4.15 
Furthermore, in 1970 the American Railways Engineering Association created a more comprehensive mathematical model described the train model properties [6]. In 1982, a further practical model was developed. The model is still widely used for computation and calculation purposes up to now [7]. The train model parameter values are obtained empirically from the train manufacturer [8-9]. However, the model parameter values from the train manufacturer compared to the real train may change due to the age and condition of the train. The discrepancy between the real and the mathematical model can lead to instability of the controlled APMS and it is unacceptable due to safety of passengers.

In this paper, the parameter values of the train mathematical model will be obtained by means of grey-box model. The Grey-box model is a mathematical representation which parameter values obtained by optimization method [10]. The objective function of this optimization method is the error between the output of the mathematical model compared to the real APMS.

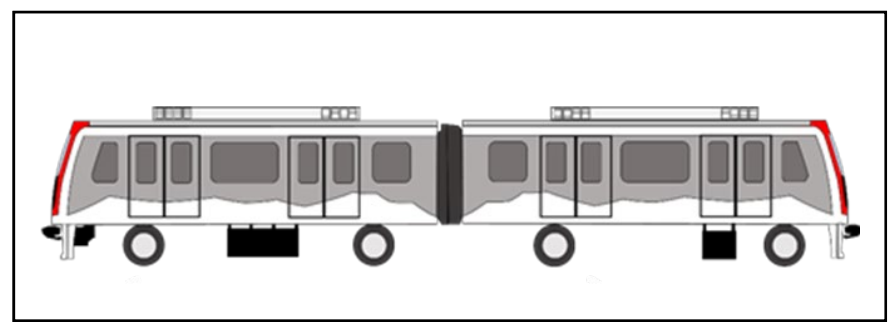

Figure 1. APMS train

\section{The Grey Box Model}

In mathematical theory, a grey-box model is a well-known method that combines the mathematical model and the real output system with the optimization method so as to improve the accuracy of the parameter values which represents real dynamics of the real system [1112]. The illustration of the grey-box model is presented as a block diagram in Fig. 2.

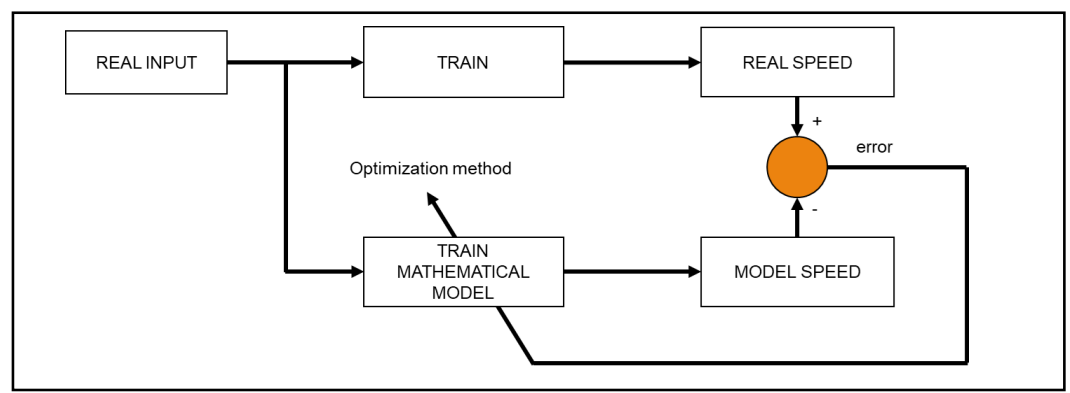

Figure 2. Grey-Box Model Block Diagram

\section{A. The Train Mathematical Model}

The dynamics of the train mathematical model is represented by (1):

$$
\frac{d v}{d t}=\frac{f(a)}{m} n_{m}-r(v)
$$

The Davis equation, denoted by (2), is a well-known train-resistance [13]:

$$
r(v)=q+b_{i} v+c v^{2}
$$

where $q$ is the resistance of train wheel rotation, $b_{i}$ is the resistance of friction between train wheel and rail, and $c$ is the resistance of air friction. Equation (3) shows the relationship between force and acceleration. 


$$
f(a)=\sigma m a+\xi(m+\phi)+\psi v^{2}
$$

It is also known from the train manufacturer that the parameter value of equation (1) and (3): $m$ for half-full condition is $105,840 \mathrm{~kg}, n_{m}=4, \sigma=0.2835, \xi=9.807 \times 10^{-3} \mathrm{~m} / \mathrm{s}^{2}, \phi=$ $3,300 \mathrm{~kg}$, and $\psi=0.261 \mathrm{~kg} / \mathrm{m}$ respectively. However, the values of $q, b_{i}$, and $c$ are unknown.

In this paper, the considered mathematical model of the APMS train is only the dynamics of the wagons. The paper does not consider the dynamics of the overall system of the APMS in the CBTC context. The behavior of the transmission signal such as latency [14-15], path loss [15-16], etc. is out of the scope of the paper.

\section{B. Data Acquisition}

Acquisition of input and output data from the APMS train is carried out after the equation of the train mathematical model is obtained. The input data consists of the acceleration of the train, and the output data received is the speed of the train. Those acceleration and speed data were taken from the CBTC subsystem called automatic train operation (ATO), which is located on the train. As an onboard system, ATO functions to control the train so that it can follow a given speed profile. In addition, ATO also receives tachometer sensor readings in the form of train speed and acceleration reference input from the driver. The weight of the train is in halffull condition when the data is collected.

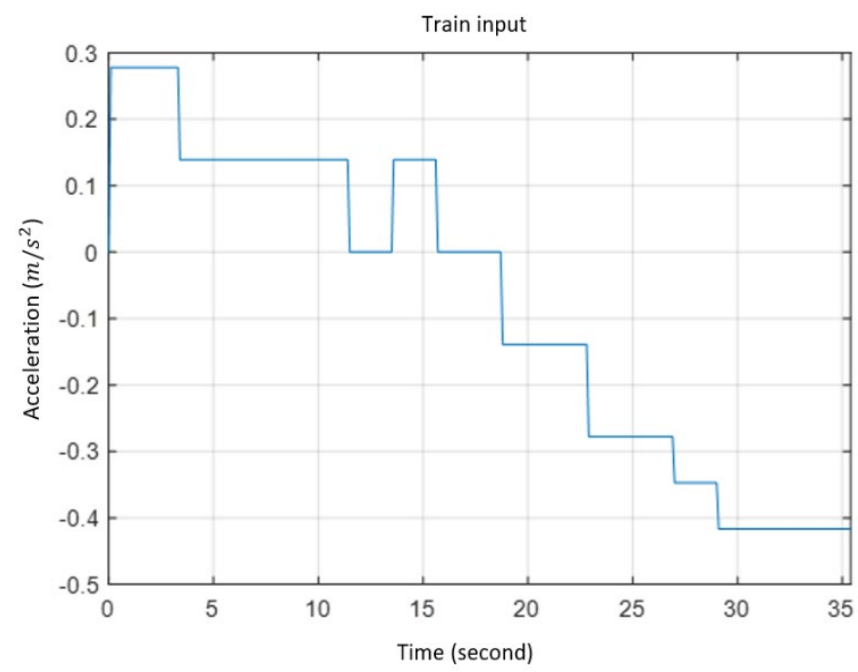

Figure 3. Train Input

Input and output data of the train are represented in the form of a Cartesian diagram with the $\mathrm{x}$-axis being the time in seconds, and the $\mathrm{y}$-axis for the input is the acceleration in $2 \mathrm{~m} / \mathrm{s}$ and for the output is the speed in $\mathrm{m} / \mathrm{s}$ shown in Figure 3 and Figure 4. The total data acquisition time is 35.4 seconds, with a time sampling of 0.1 seconds. 


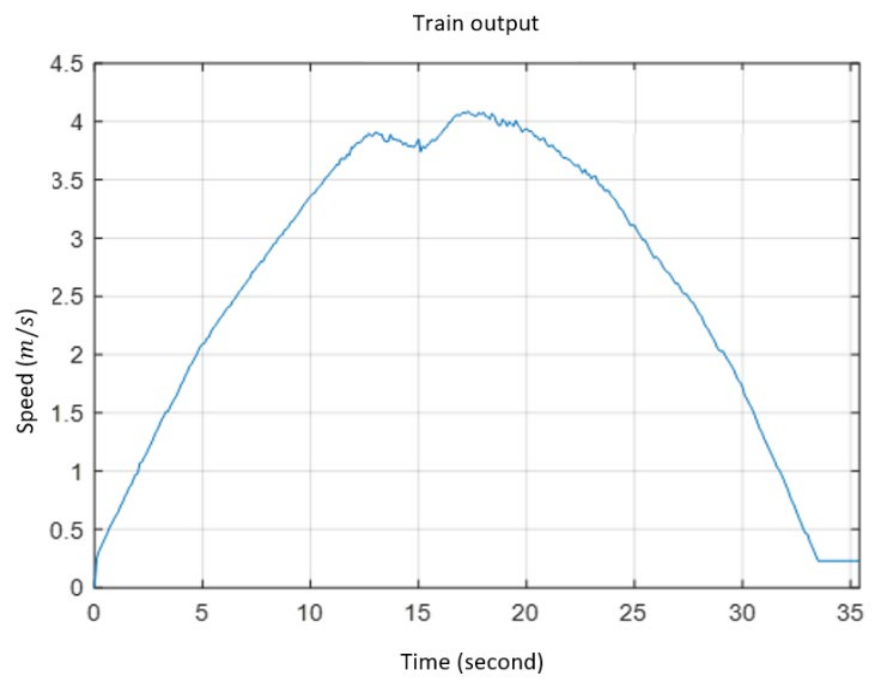

Figure 4. Train Output

\section{Optimization Method}

\section{A. GRG Algorithm}

There are several algorithms that can be used to solve nonlinear problems like GaussNewton and steepest descent methods [17]. Nevertheless, GRG algorithm in Excel has some advantages compared to them in term of robustness and reliability so that this algorithm will be used on this paper [18]. This algorithm converts inequality constraints into equality form using slack variables. This method was first developed by Lasdon et al. [19] and further by Smith and Lasdon [20]. Druid describes the full description of the method in [21].

If there is a nonlinear equation in general form, where $F\left(c_{d}\right)$ and $g\left(c_{d}\right)$ are functions that are continuous and can be derived in the domain $\left\{c_{d} \mid l \leq c_{d} \leq u\right\}$. The problem is stated as:

Minimize $F\left(c_{d}\right)$

with constraints $g\left(c_{d}\right)=b_{g}$ and $l \leq c_{d} \leq u$

Assume there is a slack variable, a variable added to eliminate the constraints, in the decision variable for all constraints, which implies that the unit matrix consists of the Jacobian value of the constraints. This matrix has a full low rank.

$$
J=\left[\begin{array}{ccc}
\frac{\partial g_{1}}{\partial c_{d 1}} & \ldots & \frac{\partial g_{1}}{\partial c_{d n}} \\
\vdots & \ddots & \vdots \\
\frac{\partial g_{m}}{\partial c_{d 1}} & \cdots & \frac{\partial g_{m}}{\partial c_{d n}}
\end{array}\right]
$$

The steps to complete the GRG algorithm can be written as follow:

1. Initialize the initial value $c_{d}$.

2. Look for a feasible solution, which must be less than an error value $\varepsilon$, where $\varepsilon>0$. If it is less than $\varepsilon$ stop the process, if else go to the step 3 .

3. Calculate Jacobian $J$ value of the constraints 
4. Choose a group of basic variables $c_{d b}$ in the basic solution whose values are not zero, so the matrix value $B_{p}$ from the base column $J$ becomes non-singular. Factorize $B_{p}$. The remaining variable is called the non-base variable $c_{d n b}$, the variable in the basic solution which has zero value $B_{p}=\frac{\partial g\left(c_{d}\right)}{\partial\left(c_{d b}\right)}$.

5. Solve the multiplier value $B_{p}^{T}=\frac{\partial F\left(c_{d}\right)}{\partial\left(c_{d b}\right)}$

6. Calculate the value of reduced gradient $r=\frac{d F\left(c_{d}\right)}{d\left(c_{d b}\right)}-J^{T} p$

7. If the $r$ value projected on the constraint is small, then the calculation is stopped because the value has reached the optimal value.

8. Look for search directions $d$ for the non-base variables $r$ and do tangential directions search

9. Do a direction search based on the search direction $d$. For each step, adjust the value $c_{d b}$ which fulfills $g\left(c_{d b}, c_{d n b}\right)=b_{g}$ by using $B_{p}$

10. Return to step 2 .

\section{A. Parameter Estimation}

In this paper, the optimization method above is used to find the unknown parameter values of the grey-box model in (2). GRG algorithm is used because (1), (2), and (3) show that the train equation is a nonlinear equation. Before implementing the GRG algorithm, the equations (1), (2), and (3) which are continuous-time functions are converted into a discrete-time function. The conversion process is carried out by using the first-order Euler method [22] as (6):

$$
v(t+1)=\left(\frac{\sigma m a(t)+\xi(m+\phi)+\psi v^{2}}{m} n_{m}-\left(q+b_{1} v(t)+c v(t)^{2}\right)\right) \Delta t+v(t)
$$

The objective function for the optimization process is represented by the root mean square error (RMSE) given by (7):

$$
\sqrt{\frac{1}{T} \sum_{i=1}^{N}(o(i)-v(i))^{2}}
$$

The optimization process is defined by minimizing (7) subject to the constraint (6) where: $q \geq 0, b_{1} \geq 0, c \geq 0$ by changing: $q, b_{1}$, and $c$.

where:

$$
\begin{aligned}
o(i) & =\text { measured train speed at } \mathrm{i}(\mathrm{m} / \mathrm{s}) \\
v(i) & =\text { speed of the train at } \mathrm{i}(\mathrm{m} / \mathrm{s}) \\
T & =\text { total time (second) } \\
i & =\text { index } \\
N & =\text { N numbers }
\end{aligned}
$$

\section{Simulation Result}

GRG algorithm is a deterministic method, which means this algorithm requires the initial values for estimating the parameter values. To minimize the RMSE value several initial values 
will be used to find the best one. From (1), it can be seen that the unknown parameters located in the second term of the equation which describes the train-resistance equation. There are three parameters that will be guessed: $q, b_{1}$, and $c$.

Finding the initial parameter values which give the lowest RMSE value would be a challenging task because the incorrect initial guess will trap the value in the local minima. Based on the known value on (1), the upper and lower bound of the three initial forementioned parameters above to give a dynamic response are between 0 to 0.7 . By knowing these boundary values, the combination of the initial values with the same step size of 0.1 for all will be put in the GRG algorithm.

Table 1. Initial values combinations

\begin{tabular}{|c|c|c|c|c|}
\hline \multicolumn{3}{|c|}{ Initial values } & \multirow{2}{*}{ RMSE } & $\begin{array}{c}\text { Number of } \\
\text { iterations }\end{array}$ \\
\hline$q$ & $b_{1}$ & $c$ & & 21 \\
\hline 0.7 & 0.7 & 0.7 & 0.013 & 19 \\
\hline 0.6 & 0.6 & 0.6 & 0.012 & 17 \\
\hline 0.5 & 0.5 & 0.5 & 0.012 & 22 \\
\hline 0.4 & 0.4 & 0.4 & 0.012 & 18 \\
\hline 0.3 & 0.3 & 0.3 & 0.012 & 20 \\
\hline 0.2 & 0.2 & 0.2 & 0.012 & 13 \\
\hline 0.1 & 0.1 & 0.1 & 0.013 & 14 \\
\hline 0 & 0 & 0 & 0.013 & \\
\hline
\end{tabular}

Table (1) shows the combination of the initial values along with the RMSE result and number of iterations. Excel Solver conducted the simulation shown by Fig. 5 with GRG algorithm implementation and 0.0001 convergence setting. This simulation will stop if the last five iterations show no significant movement.

From the result in Table (1), it can be concluded that the initial value with the least number of iterations is 0.1 and the initial value with the smallest RMSE accumulation, and the least number of iterations is 0.5 . There are two different characteristics between the convergency of the initial value of 0.1 and 0.5 . For the first one, it has a smaller initial RMSE value at the first iteration with a score of 3.426 and converges in 13 iterations. The second one has a more significant value with a score of 8.06 at the first iteration and more iteration to converge. However, it has a smaller number of RMSE accumulation of 0.013 instead of 0.012 as the first one.

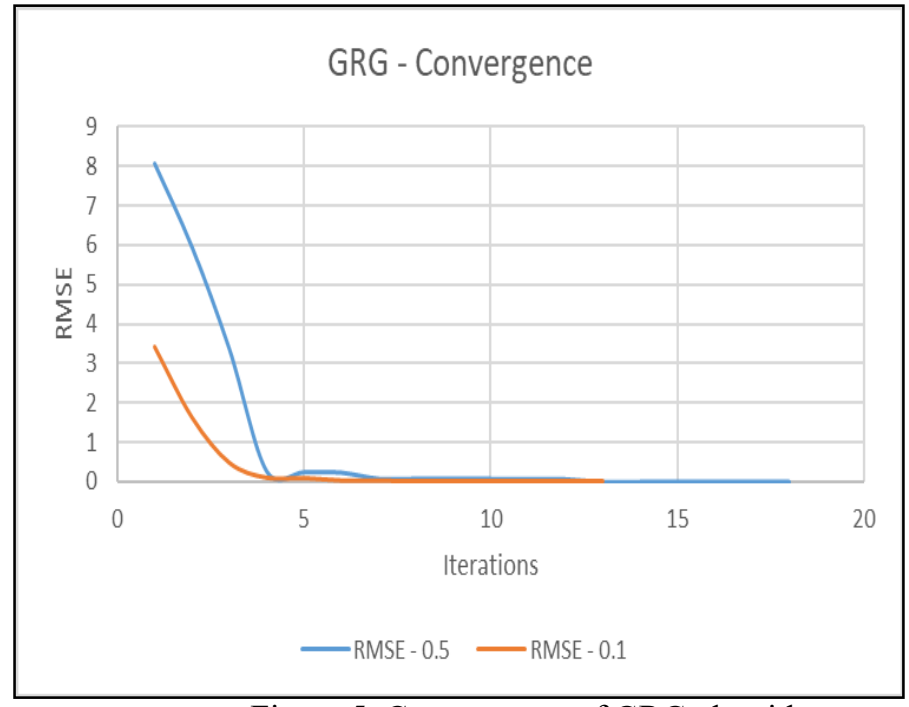

Figure 5. Convergence of GRG algorithm 
Because of the small difference between the total RMSE score between initial values of 0.1 and 0.5 , the value with smaller number of initial values and number of iterations was chosen which is 0.1 . Then, the new parameter values are found respectively $0.2 \mathrm{~m} / \mathrm{s}^{2}, 0.037 \mathrm{l} / \mathrm{s}$, dan $0.021 / \mathrm{m}$. The parameters are put back into (7), and the resulting APMS train equation model is:

$$
v(t+1)=\left(1.112 a(t)-0.16-0.037 v(t)-0.002 v(t)^{2}\right) \Delta t+v(t) .
$$

The mathematical model equation in (8) is then used to simulate the train model using the train input data and then compared with the original train output, the difference between the train output data and the simulated train model is calculated as a RMSE value equals to 0.111 . The simulation results of the obtained train model are displayed in figure 6 .

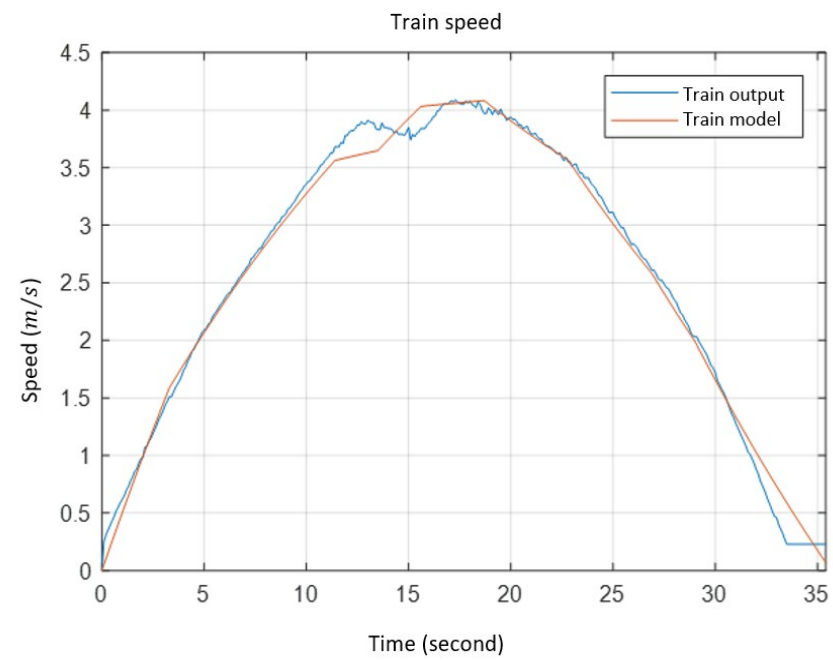

Figure 6. Simulation Results

The simulation results demonstrated that the model of the train follows the dynamics of the real train. However, in the time interval between $11.4^{\text {th }}$ and $17^{\text {th }}$ seconds, there seems to be slight difference dynamics. In Fig. 3, it can be seen that in $11.4^{\text {th }}$ second, there is a change in the input acceleration from 0.139 to 0 . The dynamics of the train model immediately follow the change in Fig. 6 with a decrease in train speed. However, at the real output, it can be seen that the decline in the speed of the new train just occurred in the $13^{\text {th }}$ second. The speed reduction is probably because, at the moment, the train is passing through an inclined path where the physical process is not included in the train model.

Equation (8) is transformed back into the continuous-time function at the end of the simulation as in (1) by arranging it as (9):

$$
\frac{v(t+1)+v(t)}{\Delta t}=1.112 a(t)-0.16-0.037 v(t)-0.002 v(t)^{2}
$$

If the limit value is set to zero, $\Delta t \rightarrow 0$ [23], it converts (9) back to a differential equation that is a nonlinear continuous-time differential equation of APMS as (10):

$$
\frac{d v(t)}{d t}=1.112 a(t)-0.16-0.037 v(t)-0.002 v(t)^{2} .
$$

\section{Conclusions}

The paper considered the modelling and validation process of the APMS model using the grey box model concept. The application of GRG algorithm in the grey-box model excellently found the unknown parameter values with RMSE value of 0.013. The simulation results showed that the created APMS model was able to follow dynamics of the original system. In the future, the created model needs to be designed by considering the shape of the train tracks, 
for example, inclining or declining on the path to get a more accurate model. The obtained mathematical model can then be used to design control systems for automatic train control purposes.

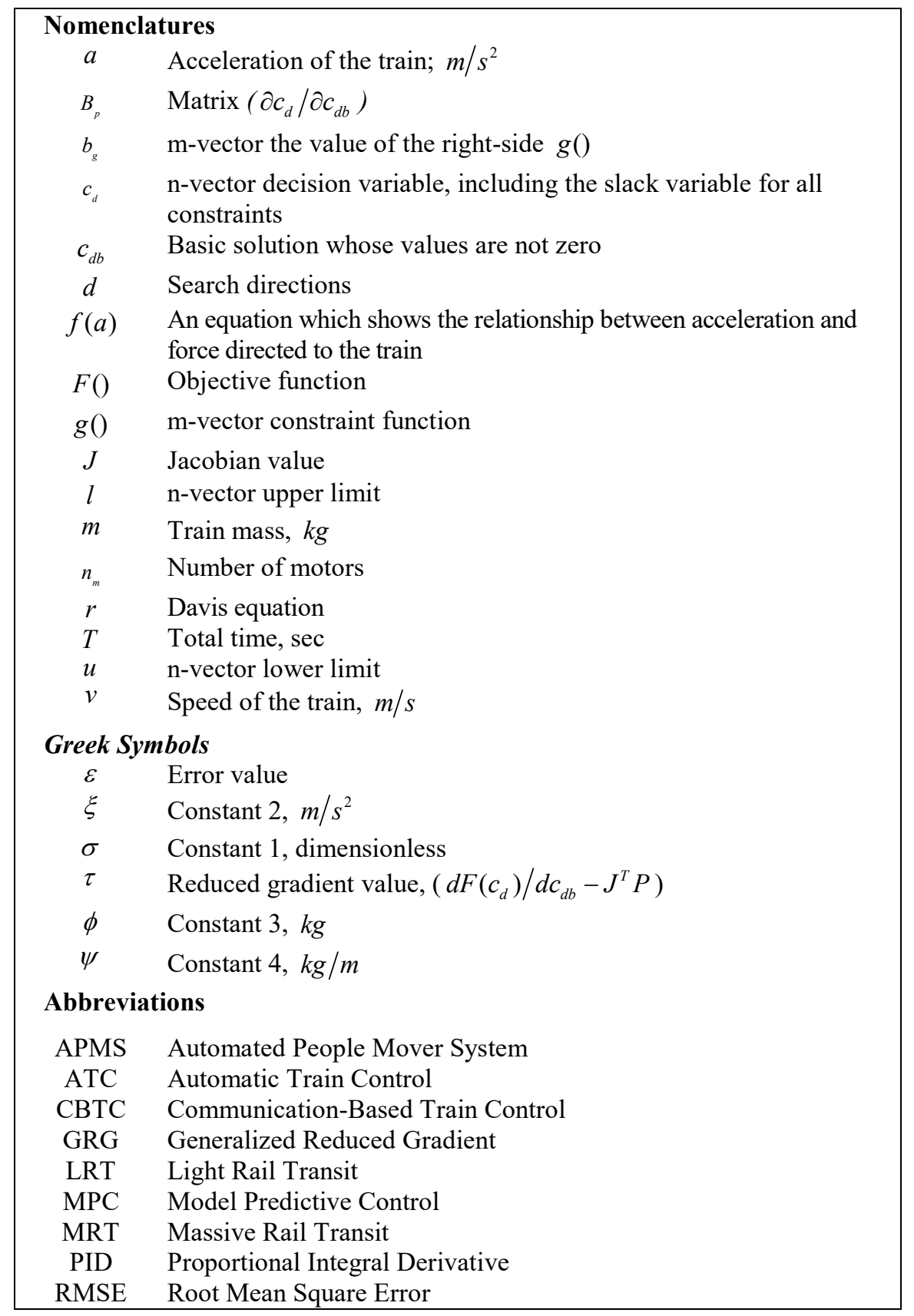

\section{Acknowledgment}

The paper was supported by Higher Education Excellent Applied Research Grant by the Ministry of Technology Research and Higher Education, Indonesia, 2018-2020. The authors would like to thank the anonymous reviewers for their valuable comments. Corresponding author E. Joelianto. 


\section{References}

[1]. L.H. Rogers, "Quiet Automated People Mover Operation in Indonesia: First Decade," Transportation Research Record, vol. 1762(1), pp. 37-39, 2001.

[2]. J.F. Britto, E.A. Perondi, and S.M.R. Sobczyk, "Dynamic Model of a Pneumatic Automatic People Mover (Aeromovel System)," International Journal of Fluid Power, vol. 15(2), pp. 101-111, 2014.

[3]. D. Abs, M. Coester, J. Detoni, D. Mori, S. Castaneda, H. Kasper, and E. Reis, "The Aeromovel Project for Airport Applications," Automated People Movers and Automated Transit Systems, pp. 41-56, 2016.

[4]. L.B. de Paula, and F.A.S. Marins, "Algorithms applied in decision-making for sustainable transport," Journal of Cleaner Production, vol. 176, pp. 1133-1143, 2018.

[5]. L.E. Suryana, and E. Joelianto, "Optimal Control for Self-Steering of a Truck System," 2018 5th International Conference on Electric Vehicular Technology (ICEVT), pp. 21-24, 2018.

[6]. Manual for Railway Engineering (Fixed Properties), Amer, Railway Eng. Assoc., Chicago, IL, 16-2-2, 1970.

[7]. W.W. Hay, Railroad Engineering, John Wiley \& Sons, 1982.

[8]. H. Dong, B. Ning, and Z. Hou, "Automatic Train Control System Development and Simulation for High-Speed Railways," IEEE Circuits and Systems Magazine, vol. 10, pp. 6-18, 2010.

[9]. Hermanto, and E. Joelianto, "Robust Optimal Control for Train Operation of 2 Car AGT (Automated Guide-way Transit) in Automatic People Movers System," 2018 5th International Conference on Electric Vehicular Technology (ICEVT), IEEE, pp. 14-20, 2019.

[10]. T.P. Bohlin, Practical Grey-Box Process Identification: Theory and Applications, Springer Science \& Business Media, 2006.

[11]. A.S. Rohman, P.H. Rusmin, R. Maulidda, E.M.I. Hidayat, C. Machbub, and D. Mahayana, "Modelling of the Mini Batch Distillation Column," International Journal on Electrical Engineering and Informatics, vol. 10(2), pp. 350-368, 2018.

[12]. E. Alibeiki and A. Khosravi, "Modelling and Control of 6MG Siemens Wind Turbine Blades Angle and Rotor Speed," International Journal on Electrical Engineering and Informatics, vol. 11(1). Pp. 80-100, 2019.

[13]. P.G. Howlett, J. Cheng, and P.J. Pudney, "Optimal strategies for energy-efficient train control”, In Control Problems in Industry (pp. 151-178), Birkhäuser Boston, 1995.

[14]. E. Joelianto, and Hosana, "Performance of an industrial data communication protocol on ethernet network," IEEE IFIP International Conference on Wireless and Optical Communications Networks, 5th WOCN'08, pp. 1-5, 2008.

[15]. E. Joelianto, and Hosana, "Loop-back Action Latency Performance of an Industrial Data Communication Protocol on a PLC Ethernet Network," Internetworking Indonesia Journal (IIJ), vol. 1(1), pp. 11-18. 2009.

[16]. E. Joelianto, M.Z. Ghazali, and T. Juhana, "Wireless Disturbance Mapping and Path Selection for Placement of Network Control System Components," Journal of Physics: Conference Series, 1230(1), 012025. 2019.

[17]. M.L. Johnson, "Why, when, and how biochemists should use the least squares," Analytical biochemistry, vol. 206(2), pp. 215-225. 1992.

[18]. A.M., Brown, "A step by guide to non-linear regression analysis of experimental data using a Microsoft Excel spreadsheet," Computers Methods and Programs in Biomedicine, vol. 65(3), pp. 191-200. 2001

[19]. L.S. Lasdon, A.D. Waren, A. Jain, and M. Ratner, "Design and Testing of a Generalized Reduced Gradient Code for Nonlinear Programming," ACM Transactions on Mathematical Software (TOMS), vol. 4(1), pp. 34-50. 1978.

[20]. S. Smith, and L. Lasdon, "Solving large sparse nonlinear programs using GRG," ORSA Journal on Computing, vol. 4(1), pp. 2-15. 1992. 
[21]. A.S. Drud, “CONOPT - a large-scale GRG code," ORSA Journal on computing, vol. 6(2), pp. 207-216. 1994.

[22]. U.M. Ascher and L.R. Petzold, "Computer methods for ordinary differential equations and differential-algebraic equations," Vol. 61. Siam, 1998.

[23]. H. Sayama, Introduction to the modeling and analysis of complex systems, Open SUNY Textbooks, 2015.

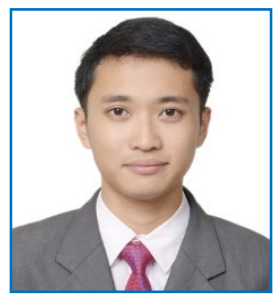

Lucas Elbert Suryana, received the bachelor degree in Engineering Physics in 2016 and the master degree in Instrumentation and Control in 2019, both from Institut Teknologi Bandung (ITB), Indonesia. He has experience as a graduate research assistant from the Artificial Intelligence, Control, and Automation Laboratory at Instrumentation and Control Research Group, Faculty of Industrial Technology, Institut Teknologi Bandung (ITB). From 2019 to 2020, he worked at Esri Indonesia as a Solution Specialist in Natural Resources Industry, which provides Geospatial Artificial Intelligence solutions. Currently, he is a lecturer at the Faculty of IT and Big Data Analytics, Institut Teknologi Calvin (ITC), Indonesia. His research interests are Control Systems, Advanced Control, Artificial Intelligence, and Geospatial Information System (GIS).

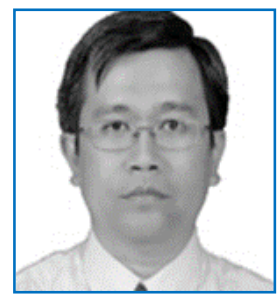

Endra Joelianto, received the bachelor degree in Engineering Physics from Institut Teknologi Bandung (ITB), Indonesia in 1990. He received Ph.D. in Engineering from The Australian National University (ANU), Australia in 2002. Currently, he is an associate professor of Instrumentation and Control Research Group and head of Artificial Intelligence, Control, and Automation Laboratory, Faculty of Industrial Technology, Institut Teknologi Bandung, Indonesia. He is a senior research fellow at Centre for UnManned System Studies (CenterUMS), Center for Defense and Security Technology, University Center of Excellence on Artificial Intelligence for Vision, Natural Language Processing and Big Data Analytic (U-CoE-AI-VLB), National Center for Sustainable Transportation Technology (NCSTT), ITB, Indonesia. His research interests are Hybrid/Discrete Event Control Systems, Advanced Control, Embedded Control Systems, Artificial Intelligence, and Intelligent Systems and Automation. He is a senior member of IEEE.

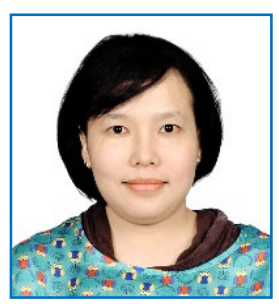

Yosi Agustina Hidayat, received the bachelor degree in Industrial Engineering from Institut Teknologi Bandung (ITB), Indonesia in 2004. She received Ph.D. in Engineering, from Hiroshima University, Japan in 2010. Currently, she is an assistant professor of Industrial System and Techno-Economics Research Group, Faculty of Industrial Technology, Institut Teknologi Bandung (ITB), Indonesia and member of International Committee of International Symposium on Scheduling (ISS) held by JIMA (Japan Industrial Management Association) since 2013. In 2013, she received LOREAL-UNESCO For Women in Science award. Her research interests are specifically related to some topics of Supplier-Buyer Relationship in Supply Chain Management, Technology Transfer Process in Supply Chain Management, Decision Analysis using Management Science Approaches in High Prevalence Diseases, Decision Science in Healthcare Industry and Logistics and Supply Chain Management of Waste. 